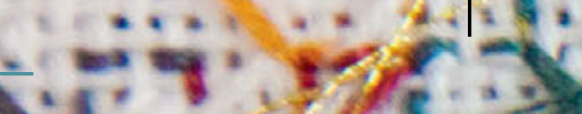

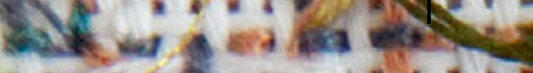



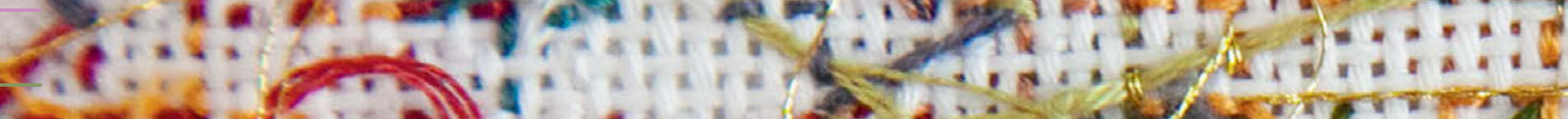

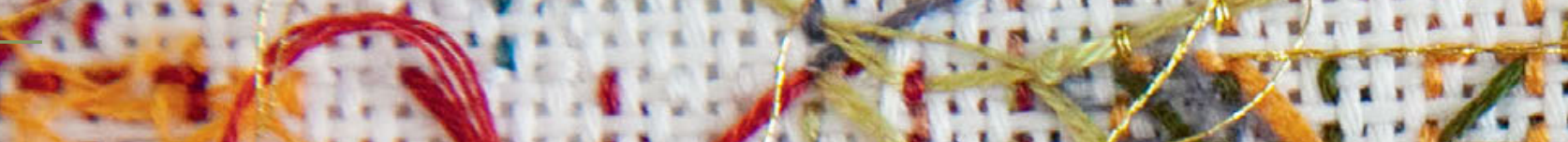

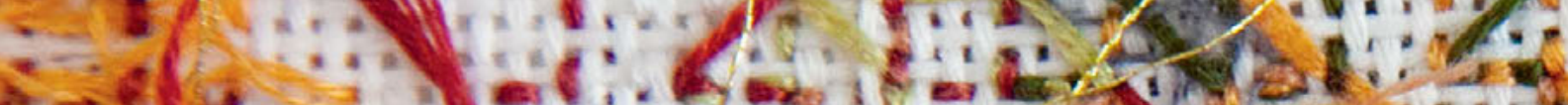

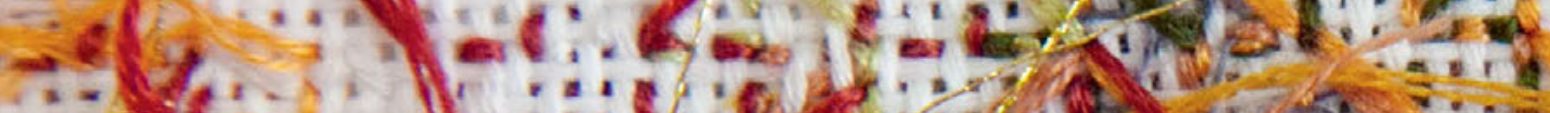

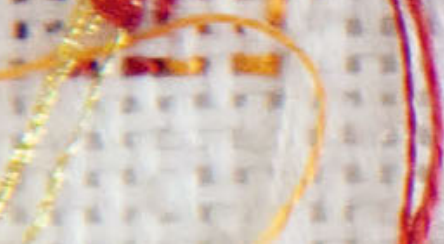

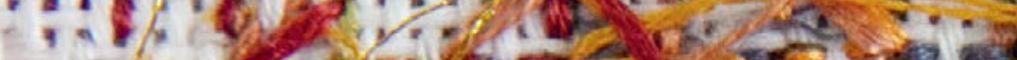

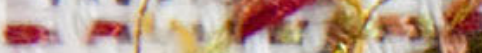

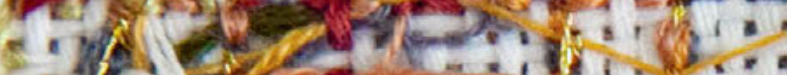

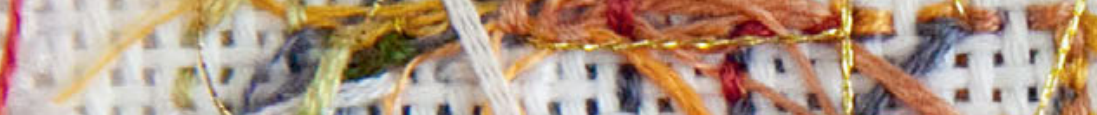

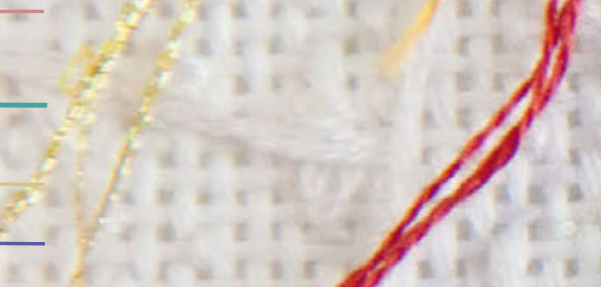

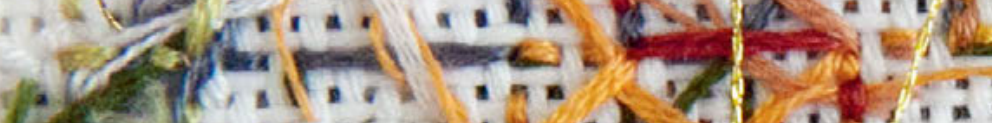

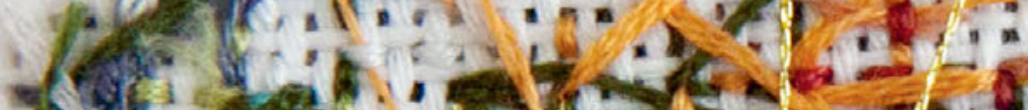

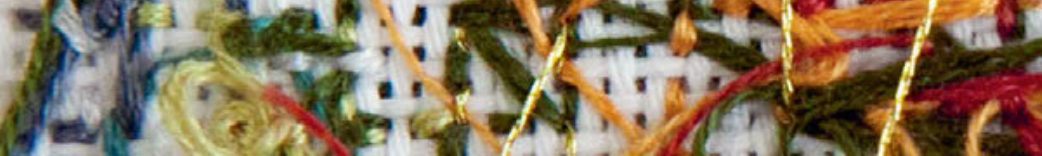

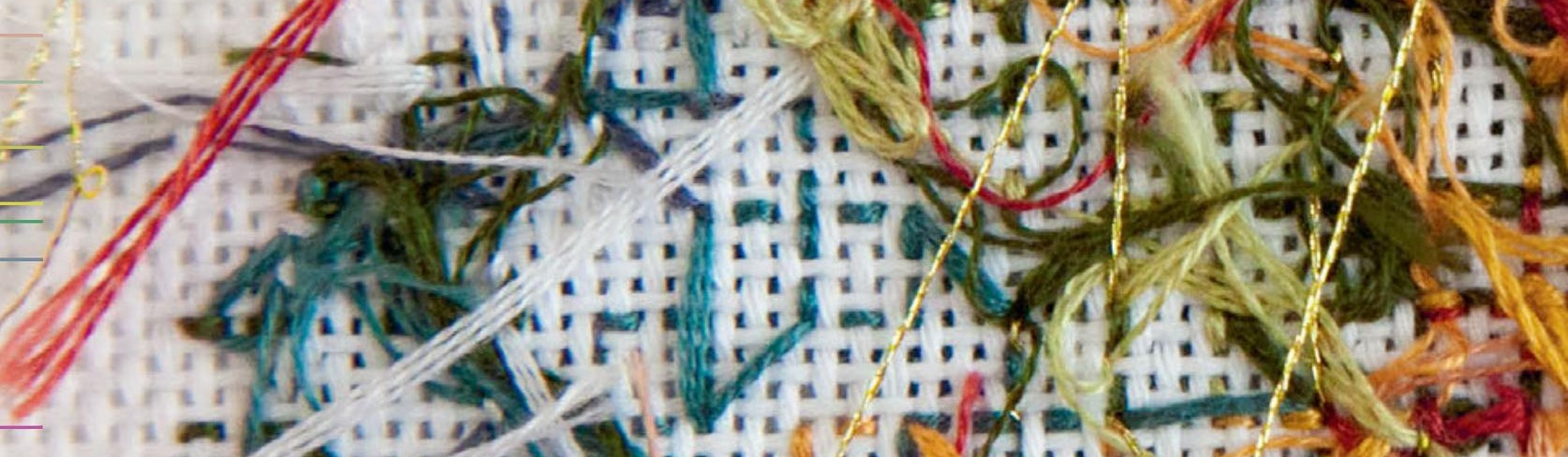

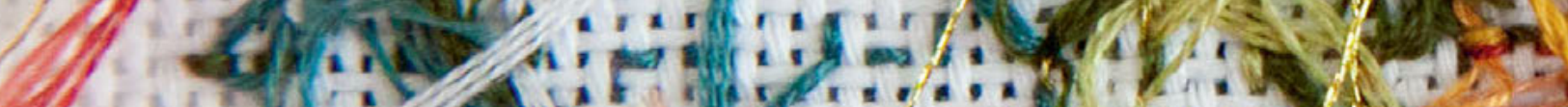

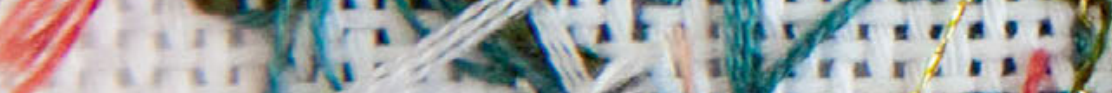

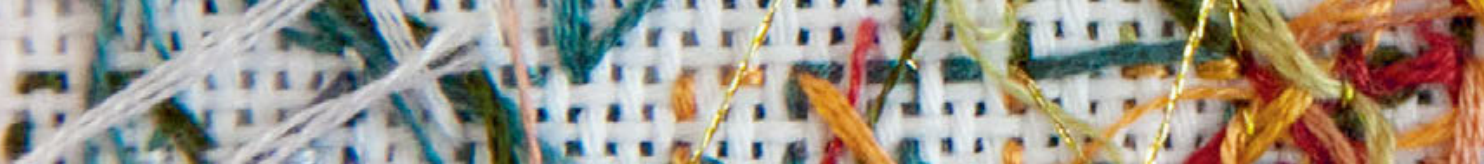

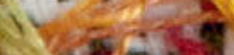

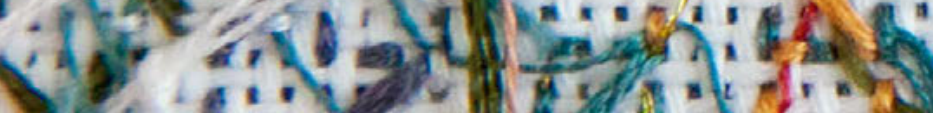
Q



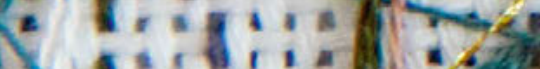

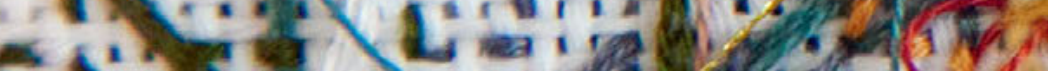
tho



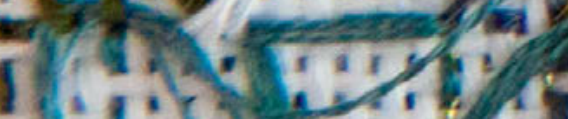

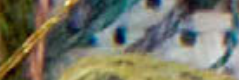

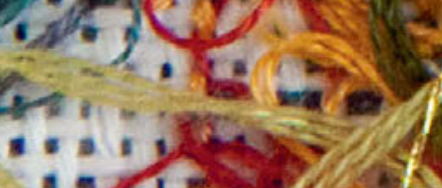

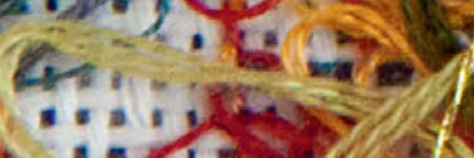

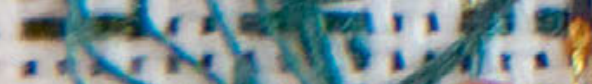

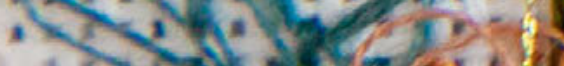

a $521 \%$

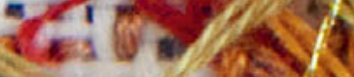

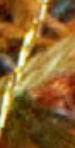

(2)

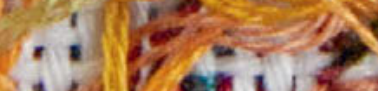

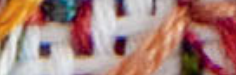

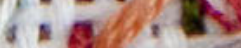
10

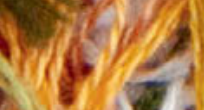

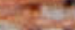

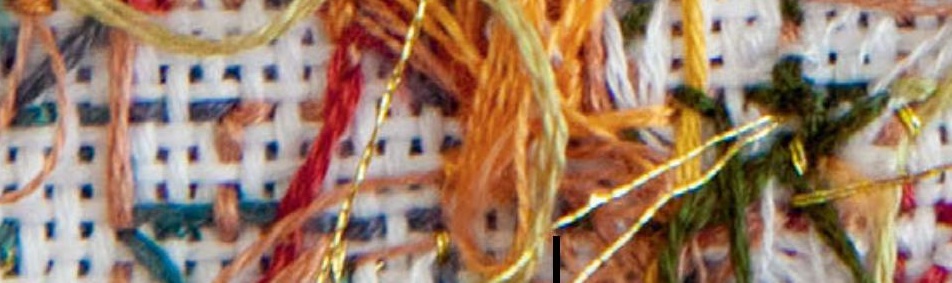




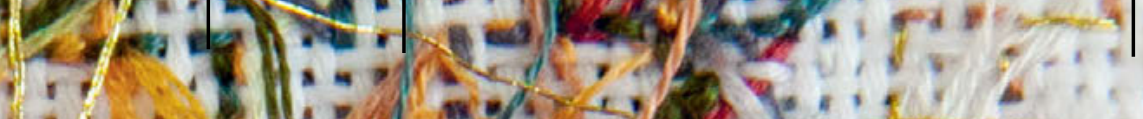

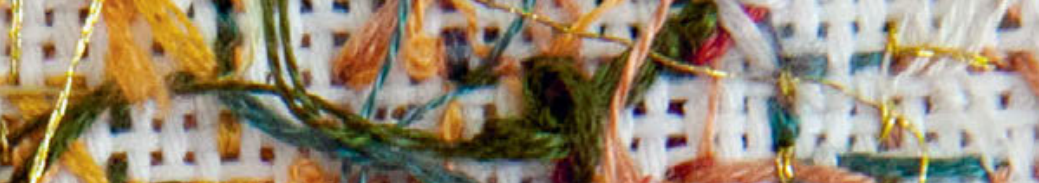

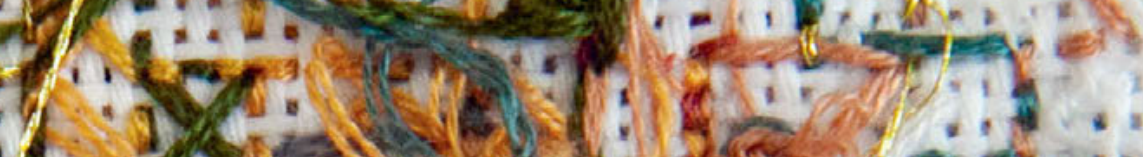

X: 6 ): $5-2$

$-2 \times 2$.

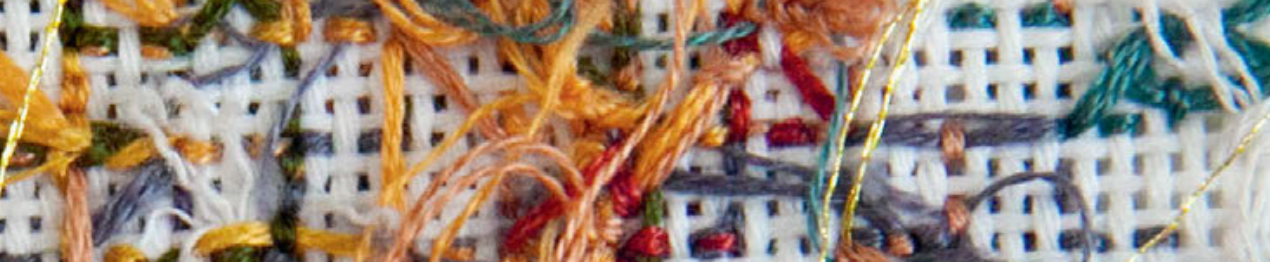

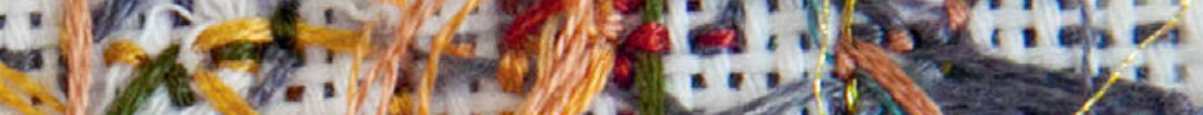


A.

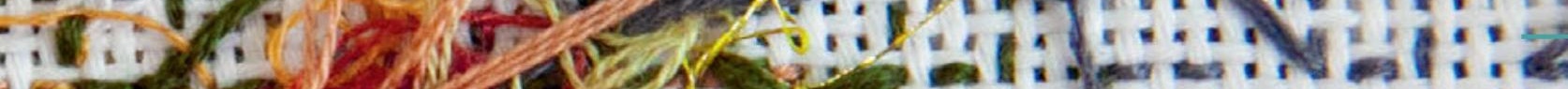

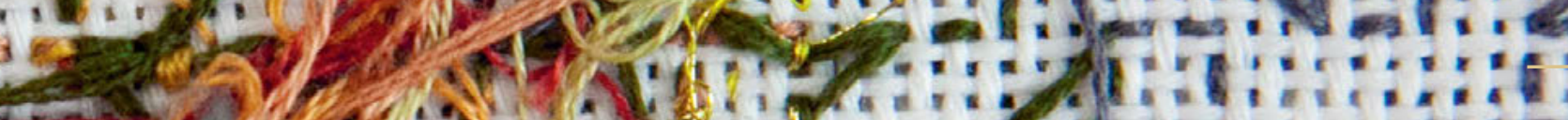

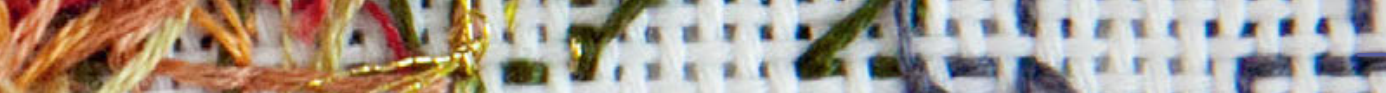

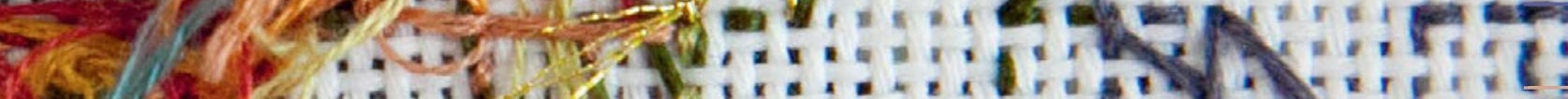

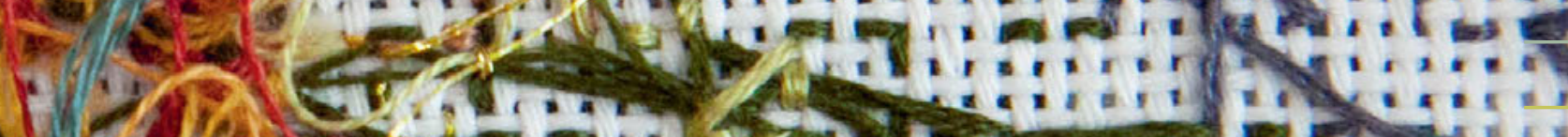

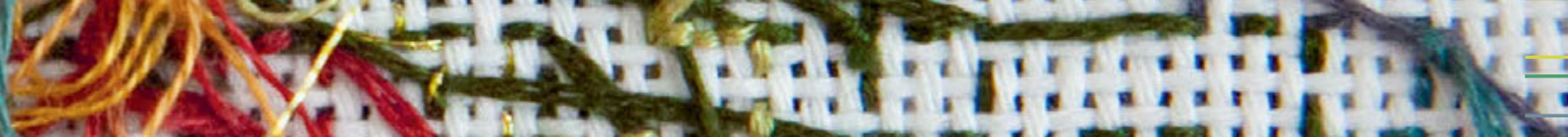

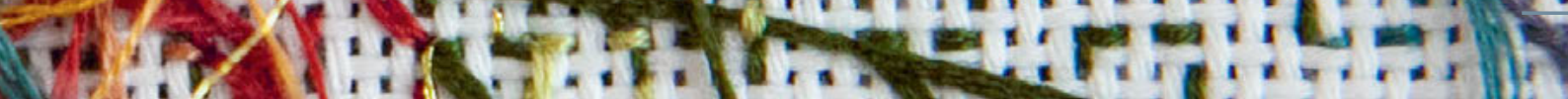

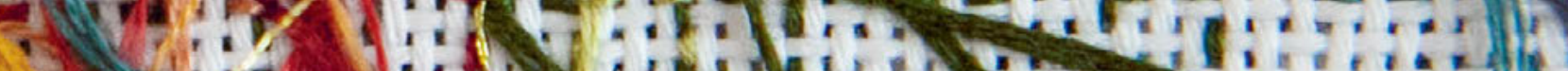

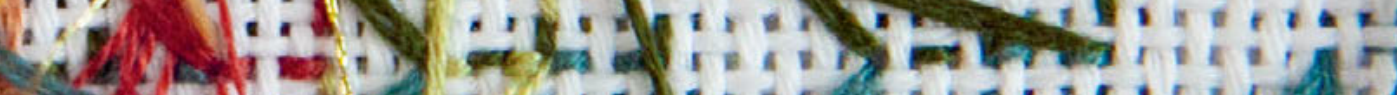
(a)


25
2

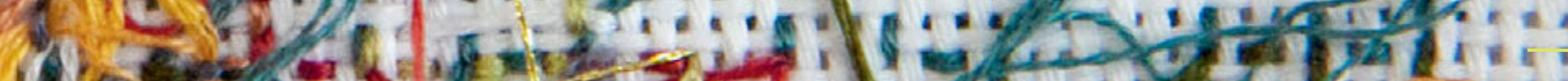

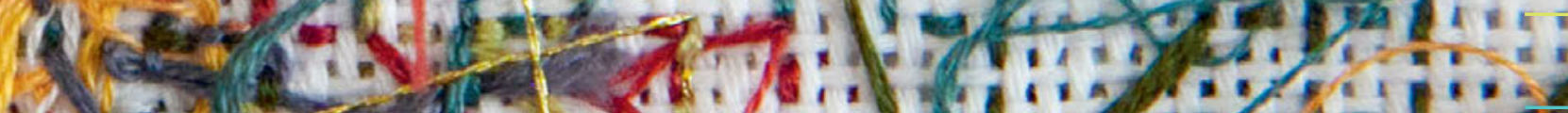

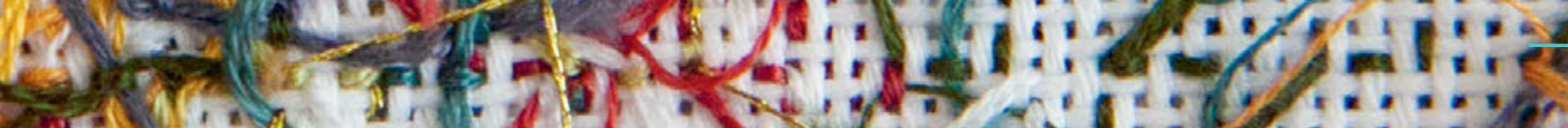

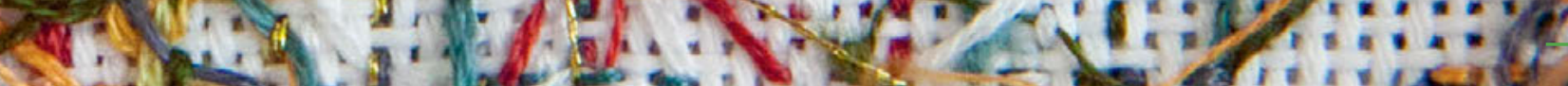

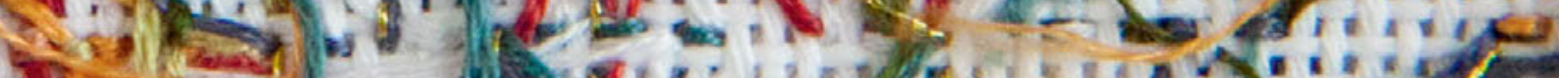
30.

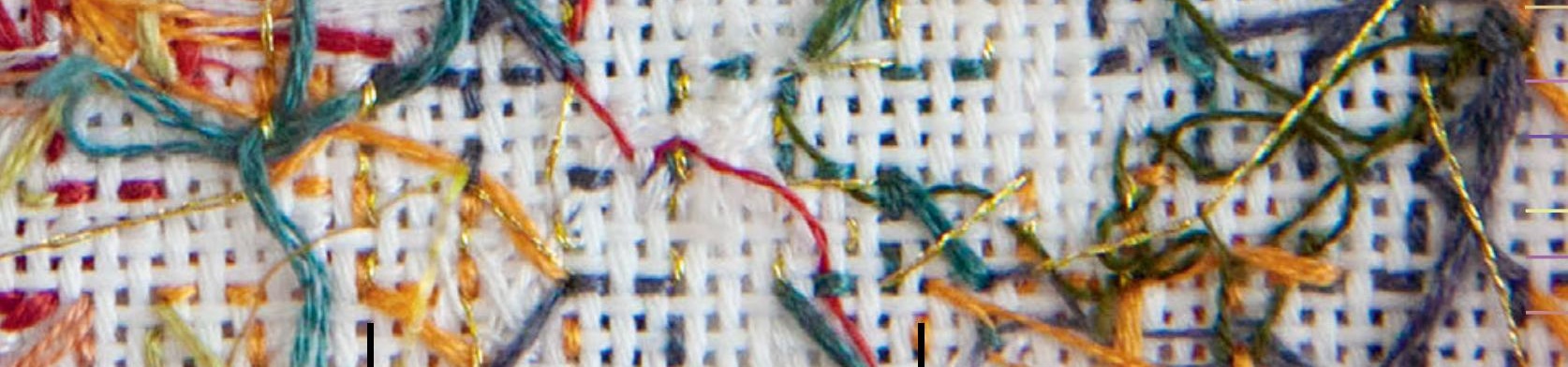




\section{Monica C. LoCascio}

* 1984 Riyadh, Saudi Arabia | Vienna, Austria

Is a multi-media artist-researcher focusing on questions of reso-

nance, connection, and interference, particularly within and between

bodies. Her work is inspired by such topics as biophotonics, somatic

therapy, and quantum theory, to memory, non-linear time, and

geometric principles. Unattached to a particular medium, she uses

research techniques to inform her explorations of form.

\section{Embrecord 3}

Embroidery, 2019

For her Embrecord series, LoCascio employs the repetitive micromovements of embroidery, a craft steeped in the traditions of storytelling, as a means of examining the processes with which the human experience can be recorded in relation to time, memory, space and perception. The stitching pattern is based on her understanding of the thermodynamics and non-linearity of time. Thread colour and length are determined by both requested external suggestions as well by her own synesthetic translations of the events she is recording. The composition at large is also not predetermined. Rather, a shape is intuitively and spontaneously embroidered that speaks to the intensity, story arch and timeframe of the event in question. The end result is an abstract colour field, which can be read by the artist like a diary. Embrecord 3 is an autobiographical record of events from December 2018 to February of 2019.

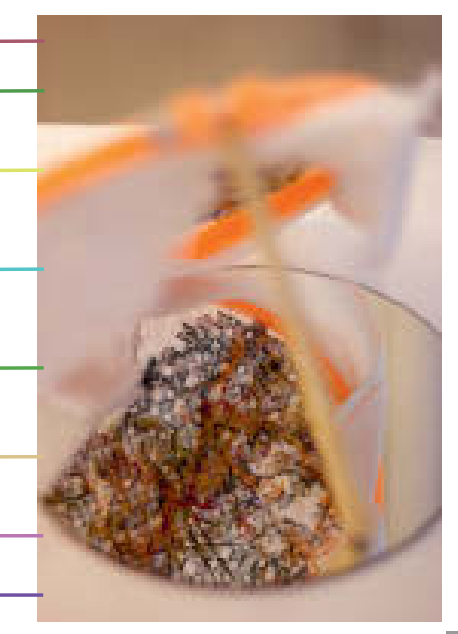


$\bigcirc$

0
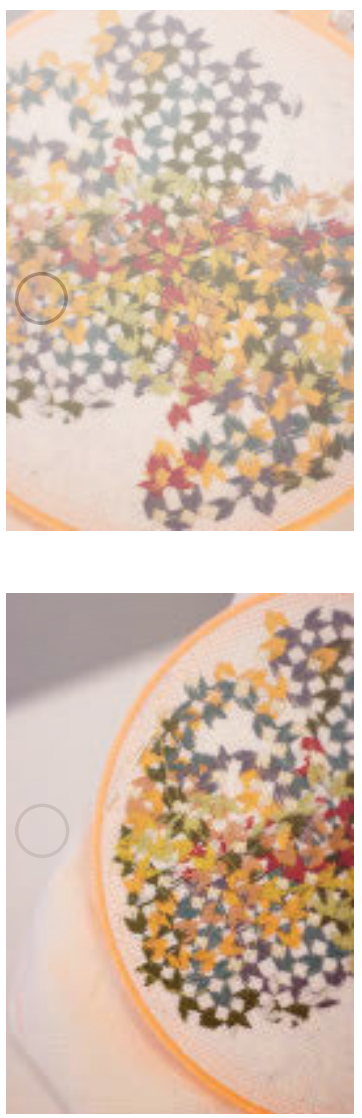
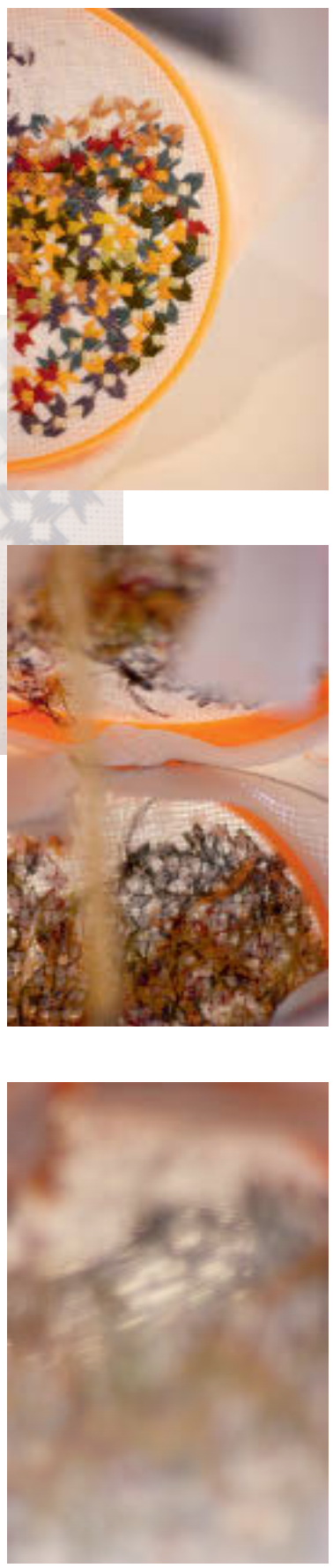



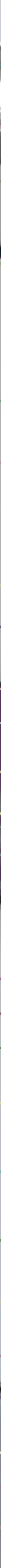